\title{
Pendidikan Keluarga pada Anak Remaja Usia 18 Tahun sebagai Solusi terhadap Tradisi Sunat Zifon di Kelurahan Batakte
}

\author{
Yunus Manafe \\ Sekolah Tinggi Teologi Sangkakala, Salatiga \\ junesmanafe87@gmail.com
}

\begin{abstract}
The family is the place where children get their first education. The family is an example that can have a big influence on their teenagers. Parents educate their children to remember traditions that can be trusted and bring happiness. The tradition of Zifon circumcision is the custom of cutting the foreskin carried out on children aged 18 years. The healing process of the wound after cutting the foreskin becomes a unique thing, namely having sex with other women after the wound heals. Researchers used qualitative research with descriptive methods and data collection using observation, interviews, and document review. This study can provide an explanation of Family Education for 18-year-old Children as a Solution to the Zifon Circumcision Tradition in Batakte Village. The existence of family education for children from the age of teenagers in order to maintain or preserve the culture or customs.
\end{abstract}

Keywords: Batakte village; family education; teenager; Zifon circumcision

\begin{abstract}
Abstrak: Keluarga sebagai tempat di mana anak pertama kali mendapatkan pendidikan. Keluarga merupakan contoh yang dapat memberikan pengaruh besar kepada anak remajanya. Orang tua mendidik anaknya untuk mengingat tradisi-tradisi yang dapat di percaya dan mendatangkan kebahagian. Tradisi sunat zifon adalah adat pemotongan kulup yang dilakukan pada anak yang berumur 18 tahun. Proses penyembuhan dari luka setelah pemotongan kulup manjadi hal yang unik yaitu melakukan hubungan seks dengan perempuan lain setelah luka tersebut sembu. Peneliti mengunakan penelitian kualitatif dengan metode deskriptif dan pengambilan data dengan menggunakan observasi, wawancara, dan telaah dokumen. Penelitian ini dapat memberikan penjelasan tentang Pendidikan Keluarga Pada Anak Usia 18 tahun Sebagai Solusi Terhadap Tradisi Sunat Zifon yang ada di Kelurahan Batakte. Adanya pendidikan keluarga kepada anak sejak berumur remaja supaya tetap mempertahankan atau melestarikan budaya atau adat tersebut.
\end{abstract}

Kata kunci: kelurahan Batakte; pendidikan keluarga; remaja; sunat zifon

\section{Pendahuluan}

Dunia mengalami perkembangan yang sangat pesat termasuk dalam bidang kesehatan. Pada saat ini banyak keluarga yang tidak melupakan tradisi dan dipertahankan sampai saat ini. Kebudayaan adalah kompleks yang mencakup pengetahuan, kepercayaan, kesenian, moral, hokum, adat istiadat, dan lain kemampuan-kemampuan serta serta kebiasaan-kebiasaan yang didapatkan oleh manusia sebagai anggota masyarakat. ${ }^{1}$ Saat ini generasi muda menjadi tongkat estafet dalam menjaga dan merawat kelestarian budaya.

\footnotetext{
${ }^{1}$ Soerjono Soekanto, "Sosiologi Suatu Pengantar" (Jakarta: PT RajaGrafindo Persada, 2014), 148.
} 
Di lingkungan pertemanan Kristen, banyak orang yang percaya bahwa salah satu hal terpenting yang bisa mereka lakukan di Pendidikan Agama Kristen (PAK) adalah membawa ananya ke gereja untuk dibaptis. ${ }^{2}$ Artinya Pendidikan Agama Kristen harus mengerjakan tentang kehidupan yang nyata kepada anak-anak, agar anak-anak mengerti tentang tujuan hidup ini. Selain mengajarkan tentang tujuan hidup, hendaknya Peran Pengajaran PAK itu mengajarkan kepada anak untuk mengenal Tuhan dengan dasar iman yang benar. Tetapi permasalahan yang sering terjadi saat ini dalam keluarga Kristen adalah masih banyak orang tua yang tidak memiliki dasar ajaran didikan Kristen yang teguh dan benar. ${ }^{3}$

Pendidikan keluarga bagi anak harus diperhatikan agar anak mendapatkan hak Pendidikan yang sebaik-baiknya. Anak yang memiliki Pendidikan yang baik dalam keluarga dapat membentuk pola pikir anak untuk berpikir dalam memutuskan sesuatu. Pendidikkan dalam keluarga adalah Pendidikan terbaik bagi anak. Pendidikan dalam keluarga dapat dipengaruhi oleh tradisi dalam keluarga. Remaja membentuk pandangan hidupnya ke luar melalui apa yang diyakini oleh keluarganya sendiri. Hal ini berkembang dengan lingkungan perhatian remaja di usia yang semakin meningkat. Karena itu, iman harus mampu menjaga seorang remaja sekaligus menerapkan strategi yang lebih detail dan mensintesa data dan nilai-nilai dalam proses pembentukan jati dirinya. ${ }^{4}$

Pendidikan remaja dapat didikan dari orang tua, karena pada saat ini remaja masih bimbang atau masih mengalami masa transisi. Ada hubungan yang harmonis antara orang tua dan anak. Jika Anda melihat seseorang yang sedang jatuh cinta pada seorang anak yang sudah remaja, orang itu akan memberi Anda nasihat tentang cara meningkatkan pendidikan dan hubungan Anda. Akibatnya, orang tualah yang pertama kali dikenal oleh anak. Kehidupan remaja dapat dikendalikan oleh orang tua dalam proses perkembangannya, agar tidak bingung dalam mengambil keputusan, tidak bingung dalam mengambil keputusan, tidak bingung dalam mengambil keputusan. Pendidikan agama dalam keluarga dapat diajarkan secara tepat bagi jiwa remaja.

Mengasuh anak pada masa remaja bisa dikatakan mudah dan sulit; Mudah karena anak sudah bisa diajak berpikir, tetapi kesulitannya adalah mereka masih dalam tahap perkembangan yang belum stabil, sehingga remaja sering menemukan permasalahan yang tidak dapat dihadapi sendiri membuatnya menjadi pemberontak. Masa remaja merupakan masa bagi anak untuk membentuk dan menguji identitas dirinya, serta mengembangkan peran interpersonalnya untuk mendapatkan pengakuan bahwa dirinya adalah orang dewasa. Mereka sering menggunakan teman sebaya dan orang dewasa di luar keluarga sebagai idola untuk dijadikan model bagi diri mereka sendiri, tetapi mengakui bahwa orang tua dan orang tua mereka masih memiliki pengaruh dalam perkembangan. ${ }^{5}$

Anak harus mempelajari berbagai hal yang ingin diketahui remaja dalam lingkungan dan suasana yang baik. Suatu budaya masuk dan memberikan contoh yang justru merusak karakter atau moral remaja. Oleh karena itu, terjadi pergeseran nilai-nilai yang ada di masyarakat, sehingga mengakibatkan zaman semakin menjauh dan mulai luntur dari nilai-nilai yang dianut-

\footnotetext{
${ }^{2}$ N.K. Atmadja Hadinoto, "Dialog Dan Edukasi Keluarga Kristen Dalam Masyarakat Indonesia" (Jakarta: PT BPK Gunung Mulia, n.d.), 10.

3 Talizaro Tafonao, "Peran Pendidikan Agama Kristen Dalam Keluarga Terhadap Perilaku Anak" 3, no. (2) (2018): 124

${ }^{4}$ Gainau Markus S, “Pendidikan Agama Kristen (PAK) Anak" (Yogyakarta: Kanisius, 2021), 122.

${ }^{5}$ Widodo, Penyelenggaraan Pendidikan Orang Tua Pasca Pemberlakuan Permendikbud No. 9 Tahun 2020 (Yogyakarta: CV Budi Utama, 2021). 38
} 
nya. Bagi orang tua, perintah Alkitab adalah mendidik anak-anak mereka dari Allah (Ef. 6:4). Pendidikan dapat ditularkan dari generasi ke generasi melalui lingkungan komunikasi, aktivitas, pikiran, dan perasaan dari tua ke muda. ${ }^{6}$

Kepribadian orang tua ditransmisikan kepada anak melalui penyerapan, yang lebih efektif daripada kata-kata. Seorang anak menyerap nilai-nilai, sikap, dan pandangan orang tuanya dan dirinya sendiri. Seringkali penularan ini terjadi tanpa disadari oleh orang tua karena banyak aspek kepribadian orang tua yang terpancar tanpa mereka sadari karena banyak aspek kepribadian orang tua yang terpancar tanpa disadari. Jika mereka tidak patuh, karakter pembohong akan diterapkan pada anak-anaknya; mereka tidak perlu berkata, "Jadilah pembohong." Alhasil, orang yang dimaksud harus memiliki kepribadian yang sehat dan dewasa. Kehidupan orang tua dapat menjadi penentu bagi kehidupan remaja.

Berdasarkan latar belakang masalah dan fokus penelitian di atas, penelitian ini dapat merumuskan sebagai berikut: Bagaimana Pendidikan keluarga kepada anak usia 18 tahun Sebagai Solusi Tradisi Zunat dan Ritual Zifon di Kupang Barat, Nusa Tenggara Timur?

\section{Metode Penelitian}

Peneliti menggunakan penelitian deskriptif. Dasar dari penelitian deskriptif merupakan suatu bentuk penelitian untuk mendeskriptifkan/ fenomena-fenomena yang ada, baik fenomena rakayasa manusia atau alamiah. ${ }^{7}$ Peneliti harus mewawancarai dan mengamati dalam pengaturan alami untuk menafsirkan kegiatan interaktif ini, untuk mendapatkan pemahaman (menurut persepsi mereka, bukan persepsi peneliti) tentang keyakinan, tujuan, dan alat. Dalam hal ini, informasi diperoleh melalui penggunaan wasilah (mediator) peneliti yang selalu tanggap terhadap situasi. ${ }^{8}$

\section{Hasil Dan Pembahasan}

\section{Pendidikan dan Pengajaran Menurut Ulangan 6:4-9}

Ulang 6:7 "Kamu harus mengajarkan semuanya itu terus menerus kepada anak-anakmu dan bicarakanlah ketika kamu duduk di rumahmu, ketika kamu sedang dalam perjalanan, ketika kamu sedang berbaring, dan ketika kamu bangun." Orang tua diberikan kepercayaan oleh Tuhan untuk mendidik anak-anaknya agar hidup sesuai dengan Firman Tuhan. Oleh sebab itu, orang tua menjadi fondasi pertama bagi anak mendapatkan pendidikan yang baik. ${ }^{9}$

\section{Pengertian Keluarga}

Secara etimologis mempunyai arti ikatan. Kata keluarga dapat diartikan juga sebagai unit social terkecil dalam masyarakat, atau suatu organisasi bio-psiko-sosio-spiritual di mana anggota keluarga terkait dalam suatu ikatan khusus untuk hidup bersama dalam ikatan perkawinan dan bukan ikatan yang sifatnya statis dan membelenggu dengan saling menjaga keharmonisan hubungan satu dengan yang lain, misalnya, ayah, ibu, dan anak. Pengertian Pendidikan keluarga adalah proses transformasi prilaku dan sikap di dalam kelompok atau unit social terkecil dalam masyarakat. Sebab keluarga merupakan lingkungan budaya yang pertama dan utama dalam menanamkan norma dan mengembangkan berbagai kebiasaan dan prilaku yang

\footnotetext{
${ }^{6}$ Noh Imbrahim Boiliu, "Filsafat Pendidikan Kristen" (Jakarta: Uki Press, 2017), 157.

7 Nana Syaodih Sukmadinata, "Metode Penelitian Pendidikan" (Bandung: PT Remaja Rosdakarya, 2011), 72.

${ }^{8}$ A. Chaedar Alwasilah, "Pokoknya Kualitatif Dasar-Dasar Merancang Dan Melakukan Penelitian Kualitatif" (Jakarta: PT Dunia Pustaka Jaya, 2011), 42.

9 _ Alkitab (Jakarta: Lembaga Alkitab Indonesia, 1991).
} 
penting bagi kehidupan pribadi, keluarga dan masyarakat. ${ }^{10}$ Penulis fokus pada pendidikan keluarga kristen.

\section{Pengertian Remaja}

Banyak tokoh yang memberikan definisi remaja, seperti DeBrum mendefenisikan remaja sebagai pertumbuhan antara masa kanak-kanak dan dewasa. Paplia dan Olda tidak memberikan pengertian remaja secara eksplisit melainkan secara Implisit melalui perngertian masa remaja (adolescence). Menurut Papalia dan Olda, masa remaja adalah masa transisi perkembangan antara masa kanak-kanak dan dewasa yang pada umumnya dimulai pada usia 12 atau 13 tahun dan berakhir pada usia akhir belasan tahun atau awal dua puluh tahun. Sedangkan Anna Freund, berpendapat bahwa pada masa remaja terjadi proses perkembangan meliputi perubahan-perubahan yang berhubungan dengan perkembangan psikoseksual, dan juga terjadi perubahan dalam hubungan dengan orangtua dan cita-cita mereka, di mana membentuk citacita merupakan proses pembentukan orientasi masa depan.

Dikemukakan oleh Badan Kesehatan Dunia (WHO) ada tiga kriteria yang digunakan; biologis; psikologis; dan social ekonomi, yakni: (1) individu yang berkembang saat pertama kali ia menunjukkan tanda-tanda seksual sekundernya sampai saat ia mencapai kematangan seksual, (2) individu yang mengalami perkembangan psikologis dan pola identifikasi dari anakanak menjadi dewasa, dan (3) terjadi peralihan dari ketergantungan social ekonomi yang penuh kepada keadaan yang lebih mandiri. ${ }^{11}$

\section{Tradisi Sunat Yahudi (Israel)}

Orang Yahudi juga memiliki dan terus mempraktekkan tradisi atau adat-istiadat, khususnya untuk anak-anak. Sebagai acara pengumuman kelahiran, bayi yang baru lahir disambut dengan musik dan pesta. Upacara penamaan dan khitanan dilakukan pada hari kedelapan jika anak yang dilahirkan laki-laki. Upacara pemberian nama untuk anak perempuan dapat dilakukan selama 2-3 bulan saat lahir. Sunat dan pemberian nama untuk anak laki-laki dan perempuan adalah perayaan yang menggembirakan bagi anak laki-laki dan perempuan. Perayaan ini akan dilakukan selama 1-2 bulan ketika bayi sudah berumur. Bayi itu disertai dengan upacara syukur atas kelahirannya yang sehat; Ungkapan terima kasih juga dilontarkan karena kesehatan sang ibu. Keluarga besar dan teman-teman datang untuk merayakan bersama. $^{12}$

Di bidang teologi Kristen, ada tradisi lama yang memandang baptisan sebagai padanan sunat Kristen. Zwingli memperluas gagasan ini dengan menyatakan bahwa baptisan lebih penting daripada sunat karena tidak termasuk penyakit atau pertumpahan darah, dan lebih inklusif dalam arti menyatakan bahwa baptisan adalah untuk bayi laki-laki dan perempuan. Baptisan adalah tanda kepunyaan suatu komunitas dalam hal ini gereja Kristen. Fakta bahwa anak itu tidak menyadari keterbelakangan ini tidak relevan: dia adalah seorang Kristen, dan baptisan adalah demonstrasi publik bahwa dia menjadi bagian dari komunitas ini. ${ }^{13}$

Hasil wawancara dengan bapak Agus Mbait mengatakan bahwa pada musim panen tiba para pemuda akan melakukan tradisi sunat zifon dan mereka akan berkumpul di suatu tempat

\footnotetext{
${ }^{10}$ Novie D.S. Pasuhuk, "Pendidikan Keluarga Yang Efektif," KURIOS 2, no. 1 (2014): 71, http://www.sttph.ac.id/e-journal/index.php/kurios.

${ }^{11}$ Khamim Zarkasih Putro, "Memahami Ciri Dan Tugas Perkembangan Masa Remaja" 17, no. 1 (2017): 25.

12 "Tim KTAK Anak Bersinar Gemilang Jaringan Peduli Anak Bangsa, Teologi Anak Sebuah Kajian" (Jakarta: PT. Suluh Cendikia, anggota IKAPI, 2019), 49.

${ }^{13}$ Alister E. McGrath, "Sejarah Pemikiran Reformasi" (Jakarta: PT BPK Gunung Mulia, 2006), 230.
} 
seperti di kebun. Si tukang sunat memerintah untuk mandi sampai kutit penisnya mengkerut. Pada saat itulah tukang sunat mulai menyunati mereka. Peralatan yang digunakan sangat tradisional yaitu bambu dan tempurung kelapa. Ada yang juga menggunkan rambut dari ekor kuda untuk penyunatan. Tukang sunat akan mengikat ujung dari kulup dan dibiarkan selama beberapa hari dan akan putus dengan sendirinya. Kepala tempurung kelapa dilubangi dan ujung dari kulup dimasukan dan setelah itu diiris kulit kelamin sampai putus.

Di rumah Bapa Y Suni telah membuka praktek sunat jadi tidak perlu lagi pergi ke sungai. Waktu praktek di buka mulai dari jam 08:00 pagi - jam 10:00 malam. la melayani sepenuh waktu selama satu minggu. Semua pasien yang datang untuk disunat semuanya berhasil dan berfungsi dengan baik, tidak ada satupun kegagalan dan komplin. Pernah ada dokter yang datang untuk menjali hubungan kerja sama. Tetapi dari pihak Bapa Suni menolak dengan alasan dirinya tidak berpendidikan. Sehingga talenta yang dia punya tidak boleh di ekspost ke depan umum agar semua orang melihat.

Cara motong kulup juga mengalami perubahan karena teknik yang dibuat oleh Bapa Suni yaitu langkah pertama: dipijit alat vital selama 5 menit, langkah kedua: alat vital di ikat dengan benang, langkah ketiga: digunting atau disayat menggunakan bambu, langkah keempat: pengobatan. Obat-obat yang disediakan berupa ramuan khusus dan juga obat yang dibeli dari apotik. Adapun cara pengobatan untuk memperbesar penis dari laki-laki dewasa yaitu dengan menggunakan tiga jenis minyak dan diurut tujuh kali secara berturut-turut. Setelah itu membersihkan dengan air hangat, langkah selanjutnya dioleskan dengan minyak khusus yang telah diracik. Dilakukan secara terus-menerus pagi dan sore dan berkelanjutan sampai pada hari keempat harus dibukus. Bahan yang dicampur seperti air kelapa muda, madu, telur ayam kampung, dan minyak dari dukun sunat. Dari ramuan ini diyakini dapat memperbesar, memperpanjang. Membuat alat vital laki-laki menjadi laki-laki yang perkasa.

Keluarga meyakini bahwa tradisi zifon menjalin hubungan yang harmonis antara generasi saat ini dengan para leluhurnya. Dalam hal ini, seorang yang melaksanakan ritual ini, ia terbebas dari segala kutuk dan kesialan yang ada. Dosa-dosa dapat diampuni agar memberikan kesuburan bagi keluarga tersebut. Setiap kehidupan dari keluarga mendatangkan berkat dari pada yang maha kuasa. Sunat zifon sendiri memiliki simbol berupa kesehatan, kebersihan, dan keperkasaan.

Di batakte tidak mengenal tradisi sunat anak, mereka lebih mengenal tradisi sunat lakilaki dewasa. Sunat saat anak masih kecil akan membuat laki-laki impoten, selain itu badannya kecil. Hanya mitos untuk mengetahui keperkasaan laki-laki lewat zifon sekali saja hilang. Mereka yang melakukan tradisi tidak perlu menyudutkan karena rasa bersalah dan berdosa karena tidak bisa menyadarkan keluarga untuk meninggalkan zifon. Tradisi zifon menjadi satu fenomena yang ada di Nusa Tenggara Timur (NTT).

\section{Solusi Terhadap Sunat Zifon Di Kupang Barat}

Melakukan sosialisasi terhadap dukun sunat tradisional dari pihak terkait seperti bekerja sama dengan dokter dalam memberikan pelatihan secara medis. Keluarga dapat memahami sunat yang sehat dan tidak menimbulkan penyakit menular yang berujung pada kematian. Dengan adanya pelatihan bisa menyadarkan para dukun sunat dan keluarga bahwa zifon tidak perlu dilakukan sesuai ritual tersebut. Hal ini, dapat di lihat sebagai faktor pencegahan yang memberikan pengajaran yang baik dengan membutuhkan hasil yang maksimal. 


\section{KESIMPULAN}

Dari hasil penelitian dan pembahasan, peneliti menyimpulkan bahwa tradisi merupakan ritual yang dilakukan dan dipertahankan oleh keluarga sebagai bagian dari masyarakat yang ada. Budaya sebagai warisan dari leluhur mereka untuk diikuti atau dilestarikan agar tidak punah atau hilang. Ritual zifon ini sebagai kegiatan yang mengharuskan laki-laki dewasa melakukan hubungan seks, sebelum menikah dengan perempuan lain setelah di sunat. Peninggalan nenek moyang ini menjadi suatu daya tarik dalam keluarga atau masyarakat yang ada di Kelurahan Batakte. Tradisi zifon punya pengaruh besar bagi kesehatan. Zifon merupakan ritual yang dilakukan oleh setiap keluarga yang yakin bahwa dengan melakukan sunat zifon dapat memberikan kebahagian tersendiri. Adat atau tradisi selalu diutamakan oleh keluarga. Anak-anak remaja diajari supaya mengerti tentang adat. Tradisi dianggap bahwa penampilan laki-laki dewasa timor lebih bersih. Jika tidak di sunat zifon di percaya bahwa orang tersebut tubuhnya akan berbau seperti hewan.

\section{REFERENSI}

. Alkitab. Jakarta: Lembaga Alkitab Indonesia, 1991.

Alister E. McGrath. "Sejarah Pemikiran Reformasi." 230. Jakarta: PT BPK Gunung Mulia, 2006.

Alwasilah, A. Chaedar. "Pokoknya Kualitatif Dasar-Dasar Merancang Dan Melakukan Penelitian Kualitatif." 42. Jakarta: PT Dunia Pustaka Jaya, 2011.

Boiliu, Noh Imbrahim. "Filsafat Pendidikan Kristen." 157. Jakarta: Uki Press, 2017.

Khamim Zarkasih Putro. "Memahami Ciri Dan Tugas Perkembangan Masa Remaja" 17, no. 1 (2017): 25.

Markus S, Gainau. "Pendidikan Agama Kristen (PAK) Anak." 122. Yogyakarta: Kanisius, 2021.

N.K. Atmadja Hadinoto. "Dialog Dan Edukasi Keluarga Kristen Dalam Masyarakat Indonesia." 10. Jakarta: PT BPK Gunung Mulia, n.d.

Pasuhuk, Novie D.S. "Pendidikan Keluarga Yang Efektif." KURIOS 2, no. 1 (2014): 71. http://www.sttph.ac.id/e-journal/index.php/kurios.

Soekanto, Soerjono. "Sosiologi Suatu Pengantar." 148. Jakarta: PT RajaGrafindo Persada, 2014.

Sukmadinata, Nana Syaodih. "Metode Penelitian Pendidikan." 72. Bandung: PT Remaja Rosdakarya, 2011.

Tafonao, Talizaro. "Peran Pendidikan Agama Kristen Dalam Keluarga Terhadap Perilaku Anak" 3, no. (2) (2018): 124.

Widodo. Penyelenggaraan Pendidikan Orang Tua Pasca Pemberlakuan Permendikbud No. 9 Tahun 2020. Yogyakarta: CV Budi Utama, 2021.

"File://C:/Users/HP/AppData/Local/Temp/Document\%20(25).Pdf." diunduh pada hari Jumaat, tanggal 28 Mei 2021, Jam 22:08 (n.d.).

"Tim KTAK Anak Bersinar Gemilang Jaringan Peduli Anak Bangsa, Teologi Anak Sebuah Kajian." 49. Jakarta: PT. Suluh Cendikia, anggota IKAPI, 2019. 